\title{
Effect of inter-fruit competition on development of physiological disorder "Aril browning" in pomegranate (Punica granatum L.)
}

\author{
Hemlata Singh $^{1^{*}}$, Nidhi Singh ${ }^{2}$ and Subhrojit Dolui ${ }^{1}$ \\ ${ }^{1}$ Department of Agricultural Biochemistry, Bidhan Chandra Krishi Viswavidyalaya , Mohanpur, Nadia-741252 \\ (West Bengal), INDIA \\ ${ }^{2}$ Department of Agricultural Biotechnology, Bidhan Chandra Krishi Viswavidyalaya , Mohanpur, Nadia-741252 \\ (West Bengal), INDIA \\ *Corresponding author. E-mail: hemlata.singh9243@gmail.com
}

Received: February 4, 2016; Revised received: July 26, 2016; Accepted: October 17, 2016

\begin{abstract}
The quality of fruits is a major factor limiting the export of fruit. One of the important causes of quality deterioration of fruits is their physiological disorder. Present study was conducted to study the effect of inter-fruit competition on physiological disorder of pomegranate(Punica granatum L.) "Aril Browning (AB)", incidence was higher in panicles with more number of fruits, i.e. panicles with two fruits had high intensity of both medium intensity $(13 \%)$ and high intensity $(2 \%)$ of $A B$ incidence in comparison to panicle with one fruit,which had $7 \%$ of medium intensity $(\mathrm{MI})$ and $1 \%$ of high intensity $(\mathrm{HI})$ of incidence. Competition among fruits was further accelerated by treating the fruits with growth regulators viz $\mathrm{GA}_{3}$ and $\mathrm{PBZ}$. The $\mathrm{GA}_{3}$ treated fruit was showing fewer incidences $(7 \%$ of $\mathrm{Ml}$ of browning affected aril and zero percentage of $\mathrm{HI}$ of incidence) over the control (15\% of $\mathrm{MI}$ and $2 \%$ of $\mathrm{HI})$ in contrast to PBZ treatment, which was showing higher incidence $(21 \%$ of $\mathrm{MI}$ and $3 \%$ of $\mathrm{HI})$. Analysis of result suggests that interfruit competition among the fruits growing at the same time leads to development of sinks of different strength. Such differences results in unequal distribution of nutrients to developing fruits which disturbs the physiology of fruit development leading to biochemical changes which ultimately leads to initiation of aril browning. Thus, this study provides evidence for the role of interfruit competition on development of the disorder.
\end{abstract}

Keywords: Aril browning, $\mathrm{GA}_{3}$, Incidence, PBZ, Pomegranate

\section{INTRODUCTION}

Pomegranate is a very important crop because of its medicinal and commercial importance. Fruit quality of commercially important varieties like cv Ganesh, cv Bhagwa is deteriorated by physiological disorder called Aril Browning (AB). In Aril browning, the affected arils becomes soft, deformed, acidic, develops an unacceptable off-flavor, light creamy-brown to dark blackish-brown in colour and unsuitable for consumption (Jalikop et al., 2010; Tehranifar and Mahmoodi Tabar, 2009). Browning of the arils starts with a tiny dark dot on the seed, which later spreads to the entire aril and many arils exhibit a streaked appearance due to fine white lines radiating from the seeds (Shivashankar et al., 2012). Like other physiological disorders, exact cause of this disorder is also not well understood. Earlier studies on many horticultural crops has shown that preharvest factors like environment conditions, nutritional status, fruit position and fruit load affect the susceptibility of crop to physiological disorders. In some wellstudied disorders, such as bitter pit in apples the preharvest factors have been relatively well defined (Ferguson and Watkins, 1989). Crisosto et al. (1997) reported that incidence of mealiness and flesh brown- ing in peaches has been found to be higher in fruit from trees with low crop loads, and higher in fruit from shaded, inner canopy positions. The severity of citrus fruit splitting is very much dependent on flower number, percentage fruit set (Rabe and Van Rensburg, 1996) as well as final crop load (Barry and Bower, 1997). The study conducted by Ali and Kelly (1992) indicated that inter-fruit competition significantly limits the growth rates in chili fruit. Reducing the number of flowers or fruits increases fruit size, improves quality, prevents alternate bearing and balances the fruit shoot ratio, leading to an increase in assimilates to fruits and shoots. The practical consequences of thinning include an increase in individual fruit weight, fruit maturity enhancement and better flower bud formation (Costal and Vizzatto, 2000).) In pomegranate Pawar et al. (1994) also reported that pruning of tree canopy reduced aril browning incidence. Since the disorder is noticed only after cutting the fruits, it is difficult to separate affected fruits from healthy fruit, thus it affects the market value of the fruit both in domestic and export market. As the exact cause of this malady is not known, remedial measures are difficult to advocate. If the problem of aril browning remains unresolved it could affect the consumption and export 
of pomegranate fruit. With these background information, an attempt has been made in present study to evaluate the effect of inter fruit completion on sink strength of fruit and its outcome as physiological disorder.

\section{MATERIALS AND METHODS}

Pomegranate (Punica granatum L.) fruits of cv. Bhagwa were collected from orchard located in the Sira district, Karnataka. Fruits were harvested at 90\% maturity. Fruits were tagged at $50 \%$ maturity stage in orchard; according to number of fruit per panical like one fruit per panicle and two fruit per panicle. Pre-harvest dip-treatment of immature fruit (at 50\% maturity) with, gibberellic acid (GA3) (growth promoter)@ 500 ppm and paclobutrazol (PBZ) (anti-gibberellin) @ 1000 ppm mixed with a non-ionic adjuvant, APSA-80@0.03\% for 1 min was carried out. Ripe fruits were cut open and the ABaffected arils were separated out from each fruit.

Percent incidence of aril browning (\%): It was calculated as ratio of weight of browned aril to the total weight of aril multiplied by 100 (Shivashankar et al, 2012).

Intensity of aril browning:

Low intensity (LI): represents occurrence of small whitish to grayish dots of the size of a pin head on the aril.

Big spot (BS) or Medium intensity (MI): represents browned spots on the aril with a diameter ranging from 1-2 mm.

High intensity (HI): represents incidence of aril browning where more than $50 \%$ area of the aril was affected by browning some of which were shriveled also.(Singh et al, 2013).

Statistical analysis: The data was statistically analyzed by subjecting to ANOVA. Critical difference values were compared at $1 \%$ levels of significance and whenever ' $F$ ' was found significant, treatment means were compared.

\section{RESULTS AND DISCUSSION}

Influence of fruit load on the incidence of disorder: The effect of number of fruit per panicle and its effect on incidence of disorder were studied. There was an increasing incidence of aril browning with increasing number of fruits per panicle (Table 1) panicles with two fruits had high intensity of both $\mathrm{MI}(13 \%)$ and HI (2\%) of $\mathrm{AB}$ incidence in comparison to panicle with one fruit, which had $7 \%$ of MI and $1 \%$ of HI of incidence. This results revealed that the inter fruit competition could be the one of the reason for development of the disorder. Nyhlen and Rootsi (1961) reported that in case of apple fruit from trees with larger crops developing more pit than that from trees bearing smaller crops. Link (2000) and Looney (1993) also reported that the fruit thinning is the most important technique in apple growing for improving fruit quality characteristics important for the fresh market, such as size and colour of the fruit. Concomitantly, the taste of the fruit represented by sugar and acid content and fruit firmness will be increased. The source-sink alteration by fruit removal and shoot trimming had impact on yield, leaf sugar metabolism and composition of berries in grape (Mota et al., 2010). Reducing the number of flowers or fruits increases fruit size, improves quality, prevents alternate bearing and balances the fruit shoot ratio, leading to an increase in assimilates to fruits and shoots. Fruit development and growth are dependent on photosynthetic carbon dioxide fixation in leaves and the translocation of sucrose, amino acids, and organic acids to the fruit cells (Ho, 1988). Fruit act as a sink for photosynthates, nutri-

Table 1. Inter-relationship between number of fruits per panicle and incidence of aril browning in pomegranate.

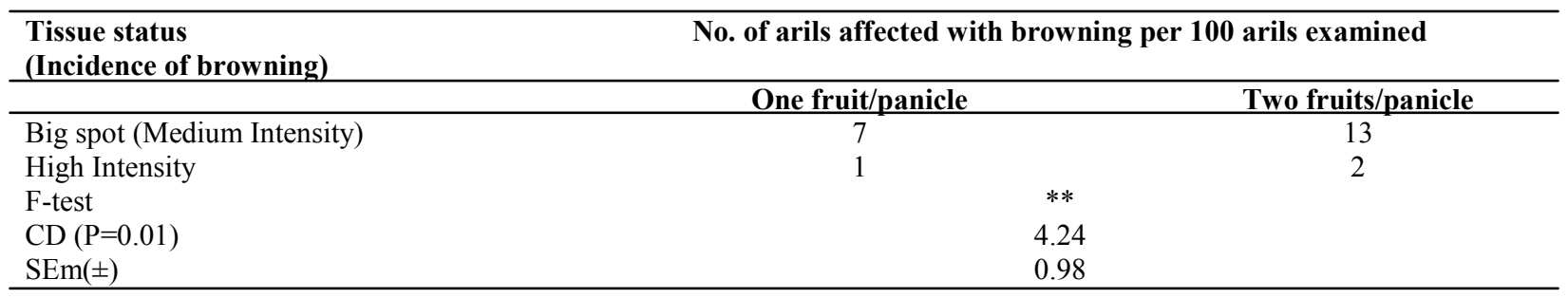

** $1 \%$ level of significance

Table 2. Intensity of aril browning in pomegranate fruits treated with growth regulators.

\begin{tabular}{|c|c|c|c|}
\hline \multirow{2}{*}{$\begin{array}{l}\text { Tissue status(Incidence of } \\
\text { browning) }\end{array}$} & \multicolumn{3}{|c|}{ No. of arils affected with $\mathrm{AB}$ per 100 arils examined } \\
\hline & Control fruit & $\mathbf{G A}_{3}$ treated fruit & PBZ treated fruit \\
\hline $\begin{array}{lll}\text { Big } & \text { spot(Medium } \\
\text { sity) } & & \end{array}$ & 15 & 7 & 21 \\
\hline High intensity & 2 & - & 3 \\
\hline F-test & & ** & \\
\hline $\mathrm{CD}$ value at $1 \%$ & & 2.419 & \\
\hline $\operatorname{SEm}( \pm)$ & & 0.611 & \\
\hline
\end{tabular}

$\mathrm{AB}$ : Aril Browing, $* * 1 \%$ level of significance 
ents and water, and when a number of fruits are present on the plant, there is a competition between different sinks. This competition among different sink affects physiology of fruit development. Plant growth regulators also affects sink strength and helps in making the developing fruit into a strong sink and mobilizing nutrients from other parts of the plant into the developing fruits (Salisbury and Ross, 1986).

Above findings on inter fruit competition among fruits were supported by the experiment of growth regulator treatment conducted and related data is presented in Table 2. $\mathrm{GA}_{3}$ treated fruits were having less incidence ( $7 \%$ of MI of browning affected aril and zero percentage of HI of incidence) as compared to control (15\% of $\mathrm{MI}$ and $2 \%$ of $\mathrm{HI}$ ) and PBZ treated fruits were having more incidences $(21 \%$ of MI and $3 \%$ of $\mathrm{HI})$. It is well known fact that plant growth regulators plays major role in altering the sink strength of plant. The growth regulator $\mathrm{GA}_{3}$ enhances the sink strength and in contrast to this, PBZ reduces the sink strength by inhibiting the biosynthesis of $\mathrm{GA}_{3}$. Several factors either endogenous or environmental conditions contribute to sink strength, but the sink activity can mainly be enhanced by GAs (Kuiper et al, 1993). Li et al. (2015) also supported this finding by proteomic analysis of the effects of gibberellin on increased fruit sink strength in Asian pear The assimilate partitioning to sink organ increases the sink strength. Sink strength is defined as the competitive ability of an organ to receive or attract assimilates (Farrar et al., 1993a). Plant growth and development depend largely upon the partitioning of assimilated carbon between photosynthetic sources such as mature leaves, and photosynthetically less active or inactive sink tissues such as flowers, roots, and fruit (Farrar et al., 2000). GA 3 influences source capacity by increasing photosynthetic potential of plants and also helps enhance sink strength by increasing assimilate transport, thus establishing its role in the source-sink system (Iqbal et al., 2011). In Japanese pear, the application of $\mathrm{GA}_{3+4}$ during the period of rapid fruit growth resulted in a marked increase in pedicel diameter and bigger fruit at harvest was reported by Zhangh et al. (2005). The application of $\mathrm{GA}_{3}$ to grape fruits enhanced fruit growth as well as the endogenous hormones (IAA or Zeatin) during fruit growth and development (Ma and Liu, 1998; Chen et al., 2000). Ugalat et al. (2013) also reported in Sapota that incidence of physiological disorder corky tissue was more in smaller fruits due to smaller sink strength. Similar results were also reported by Manoharan et al. (2015) in Sapota that competition among the fruits for assimilates on the same panicle which might in turn influence seed viability and causes corky tissue disorder. On the other hand Shivashankar et al. (2012) reporte, the formation of strong and weak sinks among arils of a fruit leads to a reduction in the moisture content of weak sinks (seeds), resulting in either a reduc- tion or complete loss of seed viability in them, which ultimately result in development of $\mathrm{AB}$.

The present data when viewed in light of past reports indicated that during the early stage of fruit development, fruits of different sink strength develop due to interfruit competition between the fruits growing at the same time, which is also regulated by growth hormones like $\mathrm{GA}_{3}$. The formation of strong and weak sink among the fruits disturbs the physiology of plant leading to development of the disorder.

\section{Conclusion}

Based on findings of this study, it may be concluded that alteration of sink strength by external application of plant growth regulators clearly shows that the incidence of browning in pomegranate might be related to the sink capacity of the fruit. The incidence of aril browning varied in direct proportion with the number of fruits per panicle. Due to interfruit competition, sink of variable strength are developed leading to unequal distribution of nutrients to developing fruits, which in turns might be responsible for physiological and biochemical changes in the fruit, eventually appearing as physiological disorder of the fruit.

\section{ACKNOWLEDGEMENTS}

I would like to express my sincere appreciation and gratitude to Dr. S. Shivashankar, Principal Scientist, Indian Institute of Horticultural Research, Bangalore for his guidance and support for the study.

\section{REFERENCES}

Ali, A.M. and Kelly, W. C. (1992). The effect of interfruit competition on the size of sweet pepper (Capsicum annuum L.) fruits. Scientia. Horticuturae, 52:69- 76

Barry, G.H. and Bower, J.P. (1997). Manipulation of fruit set and stylar-end fruit split in'Nova' mandarin hybrid. Scientia Horticulturae, 70:243-250

Chen, S.Y., Peng, Y.J. and Yang, Z.Y. (2000). Study of balanced applying fertilizer of nitrogen, phosphorus and potassium on improving fruit quality at the rapid- swelling stage of citrus fruit, Guangxi Horticulture, 4: 3-4

Costal, G. and Vizzotto, G. (2000). Fruit thinning of peach trees, Plant Growth Regulators, 31: 113-19

Crisosto, C.H., Johnson, R.S., DeJong, T. and Day, K.R. (1997).Orchard factors affecting postharvest stone fruit quality. Horticultural Science, 32:820-823

Farrar, J.F. (1993a). Forum on sink strength: what is it and how do we measure it? Plant Cell and Environment 16: 1013-1046.

Farrar, J.F., Pollock, C. and Gallagher, J (2000). Sucrose and the integration of metabolism in vascular plants. Plant Science, $154: 1-11$

Ferguson, I.B. and Watkins, C.B.(1989). Bitter pit in apple fruit. Horticultural Review, 11: 289-355

Ho, L. (1988). Metabolism and compartmentation of imported sugars in sink organs in relation to sink strength. Annual Review of Plant Physiology and Plant Molecular Biology, 39: 355-378 
Iqbal, N., Nazar, R., Iqbal, M., Khan, R., Masood, A. and Khan, N.A. (2011). Role of gibberellins in regulation of source-sink relations under optimal and limiting environmental conditions. Current science, 100 (7): 998-1007

Jalikop, S.H., Venugopalan, R. and Kumar, R. (2010). Association of fruit traits and aril browning in pomegranate (Punica granatum L.). Euphytica. 174:137 $-141$

Li, J., Yu, X., Lou, Y., Wang, L., Slovin J. P., Xu W., Wang, S. and Zhang., C. (2015). Proteomic analysis of the effects of gibberellin on increased fruit sink strength in Asian pear (Pyrus pyrifolia) Scientia Ho ticulturae, 195:25-3.

Link, H. (2000) Significance of flower and fruit thinning on fruit quality.Plant Growth Regulation, 31: 17-26

Looney, N.E. (1993) Improving fruit size, appearance, and other effects of fruit crop "quality" with plant bioregulating chemicals. Acta Horticulture, 329: 120127

Ma, H. P. and Liu, Z.M. (1998). Gibberellins and fruit tree development. Chinese Bulletin of Botany, 15: 27-36

Manoharan, S. , Shivashankar, S. and Sathisha, G.J. (2015). Influence of seed fatty acids on seed viability and corky tissue development in sapota (Manilkara achras) fruits cv. "Cricket ball". International Journal of Scinc Reserach Pubuplication, 5 (2):1-8

Mota, V.R., Souza, R.C., Silva, C.P.C., Freitas, F.G., Shiga. M.T., Purgatto, E., Lajalo. M.F. and Regina, A.M. (2010). Biochemical and agronomical responses of grapevines to alteration of source-sink ratio by cluster thinning and shoot trimming, Bragantia, 69:1

Nyhlen, A. and Rootsi, N. (1961). Corking disorder in apple. A physiological and biochemical review. Botanical review, 34:441-469
Pawar, S.K., Desai, O.T. and Choudhari, S.M. (1994). Effect of pruning on physiological disorders in pomegranates. Annal of Arid Zone, 33: 83-84

Rabe, E. and Rensburg, P.J.J. V. (1996). Gibberellic acid sprays, girdling, flower thinning and potassium applications affect fruit splitting and yield in the 'Ellendale' tangor. Journal of Horticultural Science, 71:195-203

Salisburry, B.F. and Ross, W.V. (1986). Plant physiology (Third Edition), Word Sworth Publishing Company, USA, pp $309-349$

Shivashankar, S., Singh, H. and Sumathi, M. (2012). Aril browning in pomegranate (Punica granatum L.) is caused by the seed, Current Science, 103 (1): 26-28

Singh, H., Singh, N., Marathe, A. and Ugalat, J. (2013). Influence of aril browning on biochemical properties of pomegranate (Punica granatum L.) Journal of Crop \& Weed, 9(1):184-187

Tehranifar, A. and Mahmoodi Tabar, S. (2009). Foliar application of potassium and boron during pomegraanate (Punica granatum) fruit development can improve fruit quality. Horticulture Environment Biotechnology, 50:191-196

Ugalat, J., Haradari, C. and Singh, H. (2013). Biochemical and physiological characterization of corky tissue affected fruit of sapota (Manilkara achras (Mill) Fosberg) cv. Cricket Ball. Journal of Crop \& Weed, 9 (1):193-197

Zhangh, C., Tanabe, K., Tamura, F., Matsumoto, K. and Yoshida, K. (2005). ${ }^{13} \mathrm{C}$-photosynthate accumulation in Japanese pear fruit during the period of rapid fruit growth is limited by the sink strength of fruit rather than by the transport capacity of the pedicel. Journal of Experimental Botany 56: 2713-2719 